University of Nebraska - Lincoln

DigitalCommons@University of Nebraska - Lincoln

November 1993

\title{
THE TEMPERATURE DEPENDENCE OF PERPENDICULAR ANISOTROPY IN Co/Pt AND Co/Au MULTILAYER FILMS
}

\author{
H.Y. Zhang \\ Institute of Physics, Chinese Academy of Sciences, 100080 Beijing, China \\ Y.J. Wang \\ Institute of Physics, Chinese Academy of Sciences, 100080 Beijing, China \\ G.G. Zheng \\ Institute of Physics, Chinese Academy of Sciences, 100080 Beijing, China \\ J.X. Shen \\ University of Nebraska - Lincoln \\ Z.S. Shan \\ University of Nebraska - Lincoln \\ See next page for additional authors
}

Follow this and additional works at: https://digitalcommons.unl.edu/physicssellmyer

Part of the Physics Commons

Zhang, H.Y.; Wang, Y.J.; Zheng, G.G.; Shen, J.X.; Shan, Z.S.; and Sellmyer, David J., "THE TEMPERATURE DEPENDENCE OF PERPENDICULAR ANISOTROPY IN Co/Pt AND Co/Au MULTILAYER FILMS" (1993).

David Sellmyer Publications. 107.

https://digitalcommons.unl.edu/physicssellmyer/107

This Article is brought to you for free and open access by the Research Papers in Physics and Astronomy at DigitalCommons@University of Nebraska - Lincoln. It has been accepted for inclusion in David Sellmyer Publications by an authorized administrator of DigitalCommons@University of Nebraska - Lincoln. 


\section{Authors}

H.Y. Zhang, Y.J. Wang, G.G. Zheng, J.X. Shen, Z.S. Shan, and David J. Sellmyer 


\title{
THE TEMPERATURE DEPENDENCE OF PERPENDICULAR ANISOTROPY IN Co/Pt AND Co/Au MULTILAYER FILMS
}

\author{
H.Y. Zhang, Y.J. Wang and G.G. Zheng \\ Institute of Physics, Chinese Academy of Sciences, 100080 Beijing, China. \\ J.X. Shen, Z.S. Shan and D.J. Sellmyer \\ The Center for Materials Research and Analysis, University of Nebraska, Lincoln, NE 68588-0111.
}

\begin{abstract}
We report the temperature dependence of the effective perpendicular anisotropy and interface anisotropy in the temperature region of $80 \mathrm{~K}$ to $290 \mathrm{~K}$ for $\mathrm{Co} / \mathrm{Pt}$ and $\mathrm{Co} / \mathrm{Au}$ multilayers. Different temperature dependence of the interface anisotropy have been observed for these two types of multilayers. We speculate that the strain due to the lattice misfit may not be the main reason responsible for the perpendicular anisotropy in $\mathrm{Co} / \mathrm{Pt}$ and $\mathrm{Co} / \mathrm{Au}$ multilayers.
\end{abstract}

\section{INTRODUCTION}

In recent years, the origin of the perpendicular magnetic anisotropy in Co-based multilayer films, such as $\mathrm{Co} / \mathrm{Pt}, \mathrm{Co} / \mathrm{Pd}$ and $\mathrm{Co} / \mathrm{Au}$, has been intensively investigated[1-3], and the perpendicular anisotropy is, in general, attributed to the interface or inverse magneto-striction effects $[4,5]$. Based on the band structure, theoretical calculation of such anisotropy energy has also been done for several systems[6,7].

In order to verify the explanation for the origin of the perpendicular anisotropy as mentioned above, the temperature dependence of the effective perpendicular anisotropy $\mathrm{K}_{\text {ueff }}$ and the interface anisotropy $\mathrm{K}_{\mathrm{S}}$ have been measured. These results may be helpful to further study this problem.

This paper reports the variation of $\mathrm{K}_{\mathrm{ueff}}$ and $\mathrm{K}_{\mathrm{s}}$ with temperature from 80 to $290 \mathrm{~K}$ and qualitatively discusses the origin of the perpendicular anisotropy of the $\mathrm{Co} / \mathrm{Pt}$ and $\mathrm{Co} / \mathrm{Au}$ films.

\section{EXPERIMENTAL}

$\mathrm{Co} / \mathrm{Pt}$ and $\mathrm{Co} / \mathrm{Au}$ were made by magnetron

Manuscript received February 15, 1993. This work was supported by the Chinese Natural Science Foundation, Grant No. 19274066 and the State Key Lab., of Magnetism , Institute of Physics, Chinese Academy of Sciences, Beijing 100080, China. The research at the University of Nebraska is supported by NSF Grant No. DMR-8918889. sputtering. The substrate is $\operatorname{Si}(111)$, the base pressure of the system is about $2 \times 10^{-7}$ Torr and the sputtering Ar pressure is $5 \mathrm{mTorr}$. The thickness of the individual layer is controlled by the sputtering power and time. For both $\mathrm{Co} / \mathrm{Pt}$ and $\mathrm{Co} / \mathrm{Au}$, the Co thickness is changed from 3 to $20 \AA$ and the Pt and Au thickness was fixed at $15 \AA$ and $50 \AA$, respectively. Small and large angle $\mathrm{X}$-ray diffraction (XRD) with $\mathrm{Cu}-\mathrm{K} \alpha$ radiation were used to analyze both the multilayer and
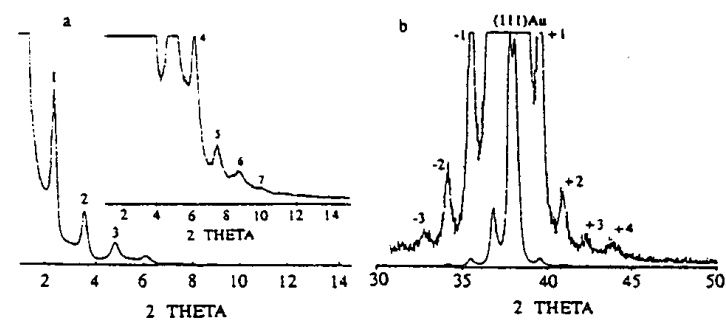

Fig. 1a and $\mathrm{lb}$. Small and large XRD pattern for Co5§A $50 \AA$

crystal structure. The effective magnetic anisotropy $\mathrm{K}_{\text {ueff }}$ and the saturation magnetization $\mathrm{M}_{\mathrm{s}}$ in the temperature range of 80 to $290 \mathrm{~K}$ were measured by magnetic torquemeter and the Quantum Design Superconducting Quantum Interference Device (SQUD) magnetometer.

\section{RESULTS AND DISCUSSION}

Small and large angle $\mathrm{X}$-ray diffraction confirms that $\mathrm{Co} / \mathrm{Pt}$ and $\mathrm{Co} / \mathrm{Au}$ multilayers have very sharp interfaces (especially for $\mathrm{Co} / \mathrm{Au}$ ). All the samples have fce structure with a pronounced (111) texture oriented along the perpendicular direction of the film plane. As an example,Figs. la and $1 \mathrm{~b}$ show the small and large XRD pattern for $\operatorname{Co} 5 \AA$ Au $50 \AA$, respectively. There are many superlattice peaks, both in the small and large angle region, which is reasonable given that $\mathrm{Co}$ and $\mathrm{Au}$ are inmiscible.

Figures 2 and 3 show the variation of $\mathrm{K}_{\mathrm{ueff}}$ with temperature for $\mathrm{Co} / \mathrm{Pt}$ and $\mathrm{Co} / \mathrm{Au}$, respectively. It can 
be seen that the temperature dependence of $K_{u e f f}$ for $\mathrm{Co} / \mathrm{Pt}$ and $\mathrm{Co} / \mathrm{Au}$ is different. As for $\mathrm{Co} / \mathrm{Au}$, the perpendicular $K_{u e f f}$ increases with decreasing

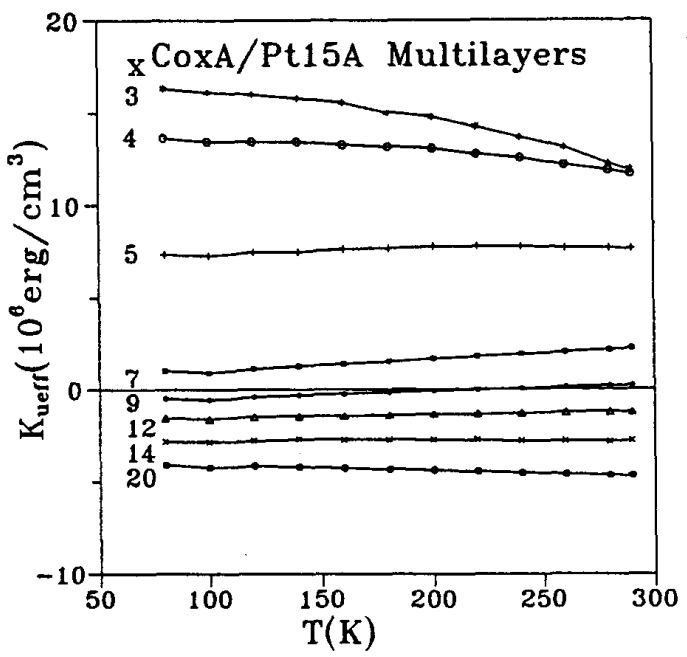

Fig.2. $\mathrm{K}_{\text {ueff }}$ vs. $\mathrm{T}$ for various Co thickness of $\mathrm{Co} / \mathrm{Pt}$. temperature, but for $\mathrm{Co} / \mathrm{Pt}$, the temperature behavior of $\mathrm{K}_{\text {ueff }}$ depends on the Co thickness. For Co thickness less than $4 \AA$, the temperature behavior of $K_{\text {ueff }}$ is similar to that of $\mathrm{Co} / \mathrm{Au}$, but for Co thicknesses over 4 $\AA, K_{\text {ueff }}$ decreases or almost stays constant when the temperature is decreasing.

In order to clarify whether this decrease of $\mathrm{K}_{\mathrm{ueff}}$ with decreasing temperature comes from the increase of the demagnetization energy, the temperature dependence of the saturation magnetization $\left(M_{S}\right)$ for

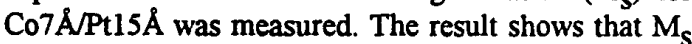
is almost independent of temperature between $4.2 \mathrm{~K}$ and $300 \mathrm{~K}$, and consequently this implies that the demagnetization energy also is independent of temperature. Therefore, it seems that $K_{\text {ueff }}$ decreasing with decreasing temperature is an intrinsic properties of $\mathrm{Co} / \mathrm{Pt}$ with the thicker $\mathrm{Co}$ layers.

The different temperature dependence of $K_{u e f f}$ for $\mathrm{Co} / \mathrm{Au}$ and $\mathrm{Co} / \mathrm{Pt}$ was reported by Sugimoto et al [8], previously. However, they. did not observe that the temperature dependence of $\mathrm{K}_{\text {ueff }}$ in $\mathrm{Co} / \mathrm{Pt}$ is closely related to the Co thickness. This might be because they only measured two $\mathrm{Co} / \mathrm{Pt}$ films. From the results obtained by both laboratories, we may conclude that the different temperature dependence of $\mathrm{K}_{\mathrm{ueff}}$ for $\mathrm{Co} / \mathrm{Au}$ and $\mathrm{Co} / \mathrm{Pt}$ (with thicker Co layer) is a common phenomenon.

In general, $\mathrm{K}_{\mathrm{ueff}}$ can be written as follows:

$$
\mathrm{K}_{\mathrm{ueff}}=2 \mathrm{~K}_{\mathrm{s}} \mathrm{t}^{\mathrm{t}} \mathrm{Co}^{+}+\left(\mathrm{K}_{\mathrm{V}}-2 \pi \mathrm{M}_{\mathrm{s}}{ }^{2}\right)
$$

where $t_{\mathrm{Co}}, \mathrm{K}_{\mathrm{V}}$ and $2 \pi \mathrm{M}_{\mathrm{s}}{ }^{2}$ are the Co thickness, volume anisotropy and demagnetization energy, respectively. The interface anisotropy $K_{s}$ can be obtained via the plot of $K_{\text {uefft }} \mathrm{Co}_{0} v s t \mathrm{Co}$. This plot can be done at different temperature and in this way the temperature dependence of $\mathrm{K}_{s}(\mathrm{~T})$ can be obtained.

Figure 4 shows the temperature dependence of $\mathrm{K}_{\mathrm{S}}$ for both systems. It clearly shows that $K_{s}$ decreases with increasing temperature for $\mathrm{Co} / \mathrm{Au}$ while $\mathrm{K}_{\mathrm{s}}$ increases with increasing temperature for $\mathrm{Co} / \mathrm{Pt}$. To our knowledge, this is the first quantitative report

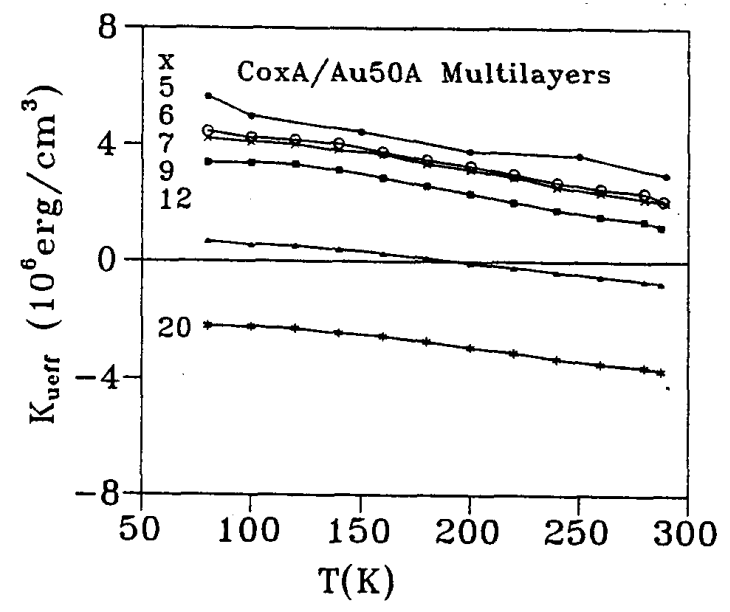

Fig.3. $\mathrm{K}_{\text {ueff }}$ vs. $\mathrm{T}$ for various $\mathrm{Co}$ thickness of $\mathrm{Co} / \mathrm{Au}$.

about the temperature dependence of the interface anisotropy $\mathrm{K}_{\mathrm{s}}$ for $\mathrm{Co} / \mathrm{Pt}$ and $\mathrm{Co} / \mathrm{Au}$. Fig. 4 also shows that the difference of the $\mathrm{K}_{\mathrm{s}}$ value for both $\mathrm{Co} / \mathrm{Pt}$ and $\mathrm{Co} / \mathrm{Au}$ become smaller when the temperature decreases and at about $80 \mathrm{~K}$ this difference vanishes.

Recently Lee et al [9] proposed that in $\mathrm{Co} / \mathrm{Au}$, the variation of perpendicular anisotropy with Co layer thickness comes from the variation of the magnetoelastic energy, which is due to the $14 \%$ lattice mismatch between $\mathrm{Co}$ and $\mathrm{Au}$ layers. It should be noted that similar lattice mismatch exists in $\mathrm{Co} / \mathrm{Pt}$. If the magneto-elastic energy is responsible for the perpendicular anisotropy, we would expect that the temperature dependence of the $\mathrm{K}_{\mathrm{s}}$ for both Co/Pt and $\mathrm{Co} / \mathrm{Au}$ would be the same. Our experimental results show that they have different behavior. Therefore, a reconsideration of the real origin of magnetic perpendicular anisotropy in $\mathrm{Co} / \mathrm{Pt}$ and $\mathrm{Co} / \mathrm{Au}$ is warranted. 


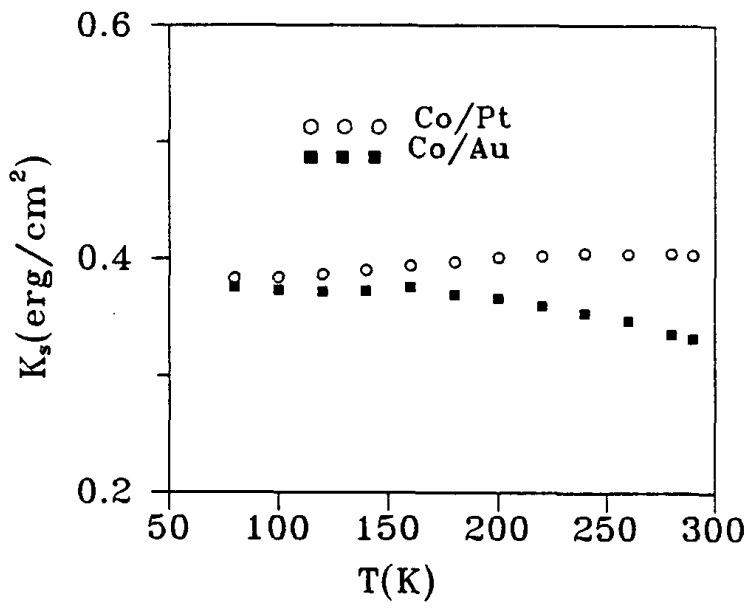

Fig.4. $\mathrm{K}_{\mathrm{s}}$ vs. $\mathrm{T}$ for $\mathrm{Co} / \mathrm{Pt}$ and $\mathrm{Co} / \mathrm{Au}$ films.

\section{REFERENCES}

[1] P.F.Carcia, A.D.Meinhaldt and Suna, Appl. Phys. Lett., 47(1985)178, P.F.Carcia, J. Appl. Phys., 63(1988)5066.

[2] F.J.A.Den Broeder, D.Kuiper, A.P.Vande Mosselact and W.Hoving, Phys. Rev. Lett., 60(1988)2769.

[3] Y.J.Wang and W.Kleemann, J. of Magn. and Magn. Materials, 115(1992)9.

[4] C.Chappert and P.Bruno, J. Appl. Phys., 64(1988)5736.

[5] S.Tsunashima, K.Nagase, K.Nakamura and S.Uchiyama, IEEE Trans. Magn., 25(1989)3761.

[6] J.G.Gay and R.Richter, Phys. Rev. Lett., 56(1986)2728, J. Appl. Phys., 61(1987)3362.

[7] A.J.Freeman and C.J.Fu, J. Appl. Phys.,
Furthermore, in the strain model, in order to get perpendicular anisotropy, both the tensile stress and the negative magnetostriction coefficient in the Co layer must be satisfied simultaneously. However, in recent years, the in-situ measurement of the stress for $\mathrm{Co} / \mathrm{Pd}$ indicates that at the beginning of the deposition, Co layer feels a compressive stress[10], and more recently, a very large perpendicular anisotropy was found in CoPt alloy films deposited by e-beam evaporation onto a heated substrate[11]. Thus, it is still a challenge to understand the detailed origins of the interface energy.

In summary, the different temperature dependence of $\mathrm{K}_{\mathrm{s}}$ for $\mathrm{Co} / \mathrm{Pt}$ and $\mathrm{Co} / \mathrm{Au}$ was found. The $\mathrm{K}_{\mathrm{s}}$ value for $\mathrm{Co} / \mathrm{Pt}, \mathrm{Co} / \mathrm{Au}$ approaches the same value with decreasing temperature and this means that $K_{s}$ is not affected seriously by the spacer materials at low temperature for the $\mathrm{Co} / \mathrm{Pt}$ and $\mathrm{Co} / \mathrm{Au}$. According to the opposite temperature dependence of $\mathrm{K}_{\mathrm{s}}(\mathrm{T})$ for $\mathrm{Co} / \mathrm{Au}$ and $\mathrm{Co} / \mathrm{Pt}$, we may conclude that the strain may be not the main origin responsible for the perpendicular anisotropy in the $\mathrm{Co} / \mathrm{Au}$ and $\mathrm{Co} / \mathrm{Pt}$ multilayer films.

61(1987)3386.

[8] T.Sugimoto, T.Katayama, Y.Suzuki, M.Hashimoto, Y.Nishihara, A.Itoh and K.Kawanishi, J. of Magn. Magn. Materials, 104-107(1992)1845.

[9] C.H.Lee, Hui He, F.J.Lamelas, W.Vavra, C.Uher and Roy Clarke, Phys. Rev., B42(1990)1066.

[10] H.Akamoto, T.Sugimoto, K.Nakagawa and A.Itoh, Magneto-Optical Recording Intemational Symposium'92, MP-6, Dec.7-9, 1992, Tucson, Arizona USA.

[11] C.J.Lin and G.L.Gorman, 37th Annual Conference on Magnetism and Magnetic Materials, CB-10, in Dec.14, 1992 Houston, Texas, USA. 